\section{Patrimônio cultural na sala de aula: reflexões a partir da utilização de metodologias}

participativas em ações de extensão universitária

\section{Rafael de Oliveira Rodrigues e Roberta de Sousa Mélo}

\section{Rafael de Oliveira Rodrigues}

Universidade Federal de Alagoas - Maceió, AL, Brasil.

E-mail: rafael.rodrigues@ics.ufal.br

ORCID: 0000-0003-1762-0655

Roberta de Sousa Mélo

Universidade Federal do Vale do São Francisco -

Petrolina, PE, Brasil.

E-mail: roberta.smelo@univasf.edu.br

ORCID: 0000-0003-1164-9190
Artigo recebido em 18 de maio de 2020 e aprovado para publicação em 25 de agosto de 2020 .

DOI: 10.33871/nupem.2021.13.28.142-158
Resumo: O objetivo deste artigo é analisar a experiência de uma ação de extensão, desenvolvida pela Universidade Federal de Alagoas, em uma escola localizada no sertão alagoano. Trata-se de refletir sobre trajetórias e os conceitos referentes ao campo do patrimônio cultural brasileiro e a importância de metodologias participativas na produção do conhecimento nas escolas. Para o alcance do objetivo proposto, foi utilizada a metodologia do Inventário Nacional de Referências Culturais, uma metodologia participativa de caráter qualitativo e etnográfico, disponibilizada pelo Instituto do Patrimônio Histórico e Artístico Nacional (IPHAN). As considerações finais apontam para dois caminhos. Primeiro, a importância da extensão universitária em incentivar a pesquisa científica na Educação Básica. Segundo, o potencial do Inventário Nacional de Referências Culturais em fomentar uma formação crítica e cidadã nas escolas.

Palavras-chave: Extensão universitária; Referências culturais; Metodologias participativas; Sertão de Alagoas. 


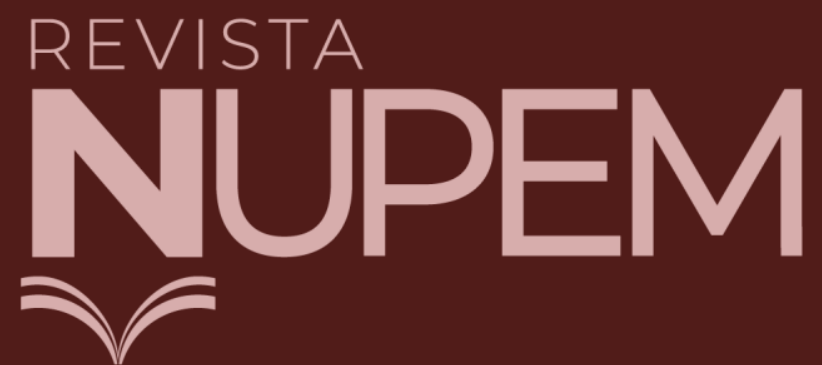

Revista NUPEM, Campo Mourão, v. 13, n. 28, p. 142-158, jan./abr. 2021

Cultural heritage in the classroom: reflections on the use of participatory methodologies in university extension actions

\section{Patrimonio cultural en el aula: reflexiones a partir de la utilización de metodologías participativas en acciones de extensión universitaria}

Resumen: El objetivo de este artículo es analizar la experiencia de una acción de extensión universitaria, desarrollada por la Universidad Federal de Alagoas, en Brasil, en una escuela situada en el interior del estado de Alagoas. Se trata de reflexionar sobre las trayectorias y los conceptos referentes al campo del patrimonio cultural brasileño y la importancia de las metodologías participativas en la producción de conocimiento en las escuelas. Para alcanzar el objetivo propuesto, se utilizó la metodología del Inventario Nacional de Referencias Culturales, una metodología participativa de carácter cualitativo y etnográfico, disponible desde el Instituto del Patrimonio Histórico y Artístico Nacional - IPHAN. Las consideraciones finales apuntan a dos caminos. Primero, la importancia de la extensión universitaria para incentivar la investigación científica en la educación básica. Segundo, el potencial del Inventario Nacional de Referencias Culturales para fomentar una formación crítica y ciudadana en las escuelas.

Palabras clave: Extensión universitaria, Referencias culturales, Metodologías participativas, Interior del estado de Alagoas. 


\section{Introdução}

Este artigo é fruto do projeto de extensão intitulado "Memória e história: um inventário do patrimônio cultural de Santana do Ipanema, Alagoas"1. Este projeto foi desenvolvido pela Universidade Federal de Alagoas (UFAL) e teve como objetivo aplicar o Inventário Nacional de Referências Culturais (INRC), uma metodologia participativa e inovadora desenvolvida pelo Instituto de Patrimônio Histórico e Artístico Nacional (IPHAN, 2000), em três escolas da cidade de Santana do Ipanema, no sertão do Estado de Alagoas. O projeto foi desenvolvido entre os anos de 2016 e 2017 e teve como meta a elaboração de uma exposição fotográfica com curadoria compartilhada entre alunos e professores da UFAL e das três escolas do município. A exposição teve como título "Memória e História: olhares sobre o sertão alagoano" e esteve em cartaz entre os dias 17 e 21 de julho de 2017, na Casa da Cultura da cidade em que foi desenvolvido o projeto.

Retomamos agora este trabalho com o objetivo de apresentar essa experiência de aplicação do INRC em uma das escolas participantes do projeto, o Colégio Cenecista, visando lançar uma reflexão sobre o potencial dessa metodologia para trabalhar questões ligadas ao campo do patrimônio cultural, especialmente sobre o tema das referências culturais na educação básica. Trata-se de discutir as trajetórias e os conceitos do campo do patrimônio cultural, a importância de metodologias participativas na produção do conhecimento e o potencial do INRC para a produção do conhecimento nas escolas.

Como já foi dito, a metodologia utilizada foi a de inventário, presente no Manual do INRC ${ }^{2}$. Em primeiro lugar, foi realizado um levantamento bibliográfico e documental no museu da cidade, o Museu Darras Noya, para a montagem de um banco de dados com fotografias representativas da cultura do sertão alagoano, especialmente da cidade onde foi realizado o projeto de extensão. Em segundo lugar, foram realizadas duas oficinas na escola, entre alunos e professores, para a seleção conjunta das fotografias mais representativas da cultura local. Em seguida, as mesmas foram catalogadas e tratadas para montagem da exposição fotográfica.

Para guiar a leitura, esse trabalho foi dividido em quatro partes, além da introdução e da conclusão. Iniciamos apresentando a metodologia do INRC (IPHAN, 2000), dando ênfase ao seu caráter inovador como ferramenta de ação social, pautada na promoção de cidadania e na aceitação da diversidade cultural. Depois disso, apresentamos detalhadamente o modo como o INRC foi aplicado no Colégio Cenecista. Dando continuidade, analisamos as formas como as referências culturais da cidade foram trabalhadas na escola. Por fim, discutimos o potencial do INRC para educação básica, especialmente no que tange ao estímulo à pesquisa entre os estudantes e à produção de uma visão crítica da sua realidade.

\footnotetext{
${ }^{1}$ Este projeto contou com recursos, por meio de bolsas de estudos, da Pró-Reitoria de Extensão da Universidade Federal de Alagoas.

2 O manual com as orientações para a aplicação do INRC encontra-se disponível para acesso público na página do IPHAN. Resumidamente, podemos dizer que essa metodologia se encontra dividida em três etapas: levantamento bibliográfico e documental, identificação das referências culturais em conjunto com o grupo ou comunidade envolvida no inventário e registro das referências culturais. Para mais informações, conferir IPHAN, 2009.
} 
As conclusões apontam para dois caminhos. Primeiro, a importância das ações de extensão desenvolvidas pelas instituições federais de Ensino Superior brasileiro, no sentido de compartilharem e produzirem conhecimento junto com as populações que habitam no entorno das universidades. Segundo, para o fato de que, enquanto metodologia participativa, o INRC (IPHAN, 2000) não se restringe apenas à identificação do patrimônio cultural institucionalizado pelas políticas públicas e o setor do turismo, tendo um grande potencial para a formação crítica e cidadã dos alunos da educação básica.

\section{Referências culturais: bases para novas metodologias participativas}

Já é lugar comum nos estudos socioantropológicos o entendimento de que as políticas públicas que envolvem o reconhecimento e a salvaguarda do patrimônio cultural brasileiro se dividem em três fases distintas (Arantes Neto, 2000; Varine, 2002; Lima Filho, 2009).

A primeira fase teve como marco a inauguração do Serviço do Patrimônio Histórico e Artístico Nacional (SPHAN), no ano de 1937. Segundo Arantes Neto (2000), o órgão fazia parte de uma série de ações coordenadas por Gustavo Capanema, Ministro da Educação do Estado Novo varguista, e tinha como objetivo a integração e consolidação do Estado-Nação brasileiro, com base em elementos culturais comuns.

A segunda fase teve início em 1970, tendo como principal característica a transformação do SPHAN no Instituto do Patrimônio Histórico e Artístico Nacional (IPHAN). Um dos marcos desse momento foi o surgimento do conceito de referências culturais, pensado como uma estratégia para fomentar um maior compromisso social por parte dos gestores públicos e das políticas voltadas para o setor. Esse período também foi marcado por um intenso processo de descentralização das políticas de identificação e salvaguarda do patrimônio, que teve como objetivo promover uma maior sustentabilidade econômica dos bens selecionados como representativos da nação brasileira.

O processo de descentralização das políticas do setor marca precisamente o momento em que o mercado turístico passa a atuar de modo mais próximo destas últimas, inaugurando a terceira fase, a das políticas de gentrificação, ou requalificação. Esta junção entre patrimônio cultural e o setor turístico transforma os lugares já reconhecidos como patrimônio em empreendimentos, produzindo-os como áreas turísticas em que os "sítios históricos e os patrimônios naturais das cidades se transformam em matéria-prima para construção de novos valores simbólicos e econômicos, produzidos como cenários de atração para o consumo" (Reis; Rodrigues, 2019, p. 70).

O patrimônio cultural se torna um recurso turístico, tendo como consequência o que Gonçalves (2007) aponta como o problema da ressonância. Em outras palavras, os elementos de importância cultural começam a ser selecionados sem se levar em conta as demandas sociais e educacionais voltadas para a cidadania, passando a ter como norte as demandas do setor turístico.

Visando diminuir tal problema, o IPHAN, juntamente com intelectuais de diferentes áreas da produção de conhecimento (antropologia, educação, história, sociologia, museologia, dentre outras), têm se esforçado para implementar uma série de metodologias inovadoras e participativas, interessadas 
em promover uma maior ressonância das políticas de patrimônio cultural para com a sociedade civil mais ampla.

Uma das metodologias desenvolvidas nesse contexto foi o INRC, a qual foi gerada a partir das experiências desenvolvidas na década de 1970 pelo Centro Nacional de Referências Culturais (CNRC), ligado ao IPHAN. Esta metodologia tem como objetivo fazer com que a sociedade civil possa auxiliar ativamente na identificação e proteção de elementos culturais. Para aplicar esse método de inventário participativo, foi produzido o Manual do INRC, que traz as orientações para a execução dessa metodologia. O documento encontra-se dividido em sete partes, sendo elas: 1) Apresentação; 2) Referências Culturais: bases para novas políticas de patrimônio; 3) Como ler INRC; 4) Processo de Trabalho; 5) Identificação do Sítio e Localidades; 6) Identificação dos Bens Culturais e 7) Montagem do Relatório.

A primeira, segunda e terceira parte do manual foram escritas por Célia Maria Corsino (2000), Cecília Londres Fonseca (2000) e Antônio Arantes Neto (2000) e têm como finalidade apresentar essa nova metodologia, focando prioritariamente em seu caráter participativo. As quatro últimas partes propõem-se fornecer instruções sobre o modo correto de preenchimento das fichas de catalogação e identificação dos bens de importância cultural, e, ao término de sua aplicação, ensinar como deve ser feito o relatório e produzido o produto final do trabalho de inventário, que consiste em um material audiovisual.

Corsino (2000, p. 8) salienta o fato de que o INRC possibilita a disponibilização de um instrumento essencial para "apreender os sentidos e significados atribuídos ao patrimônio cultural pelos moradores de sítios tombados, tratando-os como intérpretes legítimos da cultura local e como parceiros preferenciais de sua preservação". Percebe-se que o INRC é um "instrumento de ação social" (Arantes Neto, 2000, p. 27). Sobre esse potencial do INRC como instrumento de ação para a sociedade, cabe destacar que há três direcionamentos centrais para sua aplicação de forma eficiente. O primeiro, como observa Arantes Neto (2000), é a exaustividade, isto é, deve-se descrever, de forma completa e exaustiva, os elementos que compõem a cultura. Outro ponto fundamental é a sistemática de descrição dos critérios de inclusão e exclusão em se tratando dos elementos identificados como referências culturais para determinados grupos sociais. Por fim, o último direcionamento se refere à identificação das referências culturais, ou seja, uma descrição com a finalidade de identificar cada bem cultural selecionado pelo grupo, viabilizando a catalogação e registro dos bens, de modo a ser compreensível tanto para o grupo social envolvido como para um público mais amplo de especialistas.

É preciso focar, portanto, nos elementos culturais que podem ser apreendidos de forma concreta. Esses elementos são identificados através de algumas categorias-chave para guiar a coleta dos dados que comporão o inventário:

1. Celebrações. Nesta categoria incluem-se os principais ritos e festividades associados à religião, à civilidade, aos ciclos do calendário, etc. [...] 2. Formas de expressão. Formas não linguísticas de comunicação associadas a determinado grupo social ou região. [...] 3. Ofícios e modos de fazer, ou seja, as atividades desenvolvidas por atores sociais 
(especialistas) reconhecidos como conhecedores de técnicas e de matérias-primas que identifiquem um grupo social ou uma localidade. [...] 4. Edificações. Em diversos casos, estruturas de pedra e cal estão associadas a determinados usos, a significações históricas e de memória (Arantes Neto, 2000, p. 32).

Além destas, há também uma quinta categoria: "5. Lugares. Toda atividade humana produz sentidos de lugar [...] São espaços apropriados por práticas e atividades de naturezas variadas (exemplo: trabalho, comércio, lazer, religião, política, etc.), tanto cotidianas quanto excepcionais" (Arantes Neto, 2000, p. 32).

É importante enfatizar que "a seleção dos bens inventariados deve sempre ter por base o que a comunidade oferece ao conhecimento, e não o contrário" (Arantes Neto, 2000, p. 35). Cabe salientar, ainda, que a aplicação da metodologia de inventário de referências culturais encontra-se dividida em três partes. A primeira é a de levantamento preliminar, em que é realizado um mapeamento dos bens culturais. Nesta etapa utiliza-se a técnica de pesquisa bibliográfica e documental, como também entrevistas (estruturadas, semiestruturadas, de história oral) com membros do grupo participante, e também com representantes de instituições que possam oferecer material referente aos bens culturais. A segunda etapa é da identificação das referências culturais. Esta é a etapa da descrição exaustiva e sistemática do bem cultural selecionado. Nesse momento são preenchidas as Fichas de Identificação (confeccionadas a partir das cinco categorias definidas pelo INRC: ofícios e modos de fazer, formas de expressão, celebrações, edificações e lugares), com o intuito de fazer uma descrição densa e detalhada das principais características culturalmente relevantes. A terceira e última etapa de trabalho é a documentação, ou seja, a elaboração de um estudo, visando à produção de um relatório e um documento audiovisual, seja fotográfico ou fílmico, utilizado para complementar a instrução do processo de registro. Ao final destas três etapas de trabalho, o produto final elaborado de forma participativa deve ser inserido no banco de dados do INRC/IPHAN.

Após um contato prévio com essa metodologia, resolvemos aplicá-la junto a professores e estudantes do Colégio Cenecista de Santana do Ipanema (Alagoas), visando identificar elementos da cultura e da paisagem local para a elaboração de uma exposição fotográfica com curadoria coletiva, em conjunto com alunos e professores da escola.

\section{O INRC e as experiências compartilhadas no campo da educação}

Seguindo as orientações do manual de aplicação do INRC (IPHAN, 2000), demos início ao primeiro passo do nosso trabalho, a saber: definir as razões das nossas escolhas pedagógicas ${ }^{3}$. Uma vez que o INRC procura estimular e enfatizar as experiências locais na identificação das referências culturais, optamos pela adoção de uma perspectiva pedagógica local. Procuramos priorizar os elementos representativos da cultura sertaneja como ponto de partida para realização da atividade. Outro princípio pedagógico central, também com aderência ao INRC, foi o estímulo à produção de

${ }^{3}$ No ano de 2016, o IPHAN divulgou a publicação intitulada "Educação patrimonial: inventários participativos", voltada especificamente para a prática pedagógica, mas como o projeto de extensão que deu base para este artigo também foi iniciado em 2016, optamos por utilizar apenas o INRC. 
narrativas comunitárias, visando incentivar alunos e professores a utilizarem como ponto de partida suas lembranças e memórias na produção de narrativas afetivas sobre o sertão de Alagoas, a partir das categorias lugares, celebrações, ofícios e modos de fazer, edificações e formas de expressão. Por fim, também delimitamos como princípio pedagógico central da atividade o incentivo à pesquisa na escola, estimulando os alunos a vivenciarem o processo de produção de conhecimento por meio do método científico, a partir da experiência com a metodologia de inventário.

Definidas essas escolhas pedagógicas, iniciamos a aplicação do INRC propriamente dita, dividindo a equipe executora do projeto de extensão. O grupo formado por 12 estudantes dos cursos de ciências contábeis e economia, do Campus do Sertão (UFAL), na cidade de Santana do Ipanema, além dos professores, foi dividido em três equipes. A primeira ficou responsável pelo levantamento bibliográfico e documental. Foi delimitado como ambiente para esta primeira fase o Museu Darras Noya, instituição de referência local para pesquisa historiográfica. Essa equipe contatou os responsáveis pela instituição para iniciar o levantamento de imagens, documentos e material historiográfico que pudessem auxiliar na construção de um panorama com informações socioculturais, históricas e geográficas da cidade e do sertão de Alagoas.

Enquanto isso, a segunda equipe ficou responsável por visitar a escola pré-selecionada para o desenvolvimento do projeto, apresentar nossa proposta e verificar a possibilidade da aplicação do inventário. O contato inicial com a escola e o agendamento prévio das atividades ocorreu através de uma conversa informal com os diretores das instituições. Explicamos aos responsáveis que estávamos desenvolvendo um projeto que tinha como finalidade a seleção de imagens representativas da cidade e do sertão de Alagoas, de forma conjunta entre a UFAL e a escola, para a montagem de uma exposição fotográfica. Informamos que essa exposição seria feita com base na metodologia participativa do INRC, proposta pelo IPHAN (2000). Depois disso, foram enviados ofícios às equipes pedagógicas das escolas, juntamente com cópias do projeto de extensão, com o intuito de formalizar o trabalho. Por fim, foram definidas as datas para a aplicação do INRC, a qual se daria através de duas oficinas para os alunos e professores da escola, elaboradas pela terceira e última equipe responsável pela execução do projeto ${ }^{4}$.

Tratando um pouco mais sobre o trabalho das equipes executoras do projeto, foi feita uma seleção prévia de 500 fotografias nos arquivos do museu da cidade. Dessas imagens pré-selecionadas inicialmente, foram escolhidas 100 imagens representativas da cultura sertaneja (especialmente da cidade de Santana do Ipanema), para serem trabalhadas nas oficinas. Os critérios de seleção deste número reduzido de imagens foram, primeiro, a qualidade das fotos, motivo pelo qual optamos por fotografias que demandariam menos tempo no tratamento e correções para a futura exposição fotográfica. Além disso, entendemos que a quantidade estabelecida facilitaria o trabalho de escolha por parte dos alunos e professores, uma vez que havia um tempo predeterminado para realização do projeto na escola, levando-se em conta tanto o calendário escolar quanto o cronograma de execução do projeto de extensão.

${ }^{4}$ Ao todo foram desenvolvidas seis oficinas, duas em cada uma das três escolas parceiras. 
Em seguida foi realizada a seleção dos alunos da escola que participariam do projeto de extensão. Optamos, juntamente com a equipe pedagógica da escola e os professores de história, português e geografia, por desenvolver o projeto com alunos das turmas de primeiro e segundo anos do ensino médio, considerando as demandas do Exame Nacional do Ensino Médio (ENEM), as quais exigiam maior concentração dos discentes do terceiro ano.

Feito o agendamento das oficinas no Colégio Cenecista, iniciamos a segunda fase de aplicação do INRC (IPHAN, 2000): a identificação das referências culturais locais por parte dos alunos e professores. Na primeira oficina, iniciamos o trabalho com a apresentação dos conceitos de patrimônio cultural e referências culturais. Utilizamos o argumento de Arantes Neto (2000) de que as referências culturais seriam as práticas culturais representativas dos diversos grupos sociais que compõem a sociedade brasileira. Depois desta esta introdução geral, utilizamos slides em que se apresentavam algumas referências culturais brasileiras, como, por exemplo, a Serra da Barriga, no Quilombo dos Palmares, na cidade de Palmares, lugar de referência importantíssimo para o Estado de Alagoas, e o Círio de Nazaré, celebração representativa da religiosidade de Belém do Pará. Os conteúdos apresentados mencionavam também festividades, modos de fazer, enfim, exemplos das referências culturais sintetizadas através das categorias definidas pelo INRC (IPHAN, 2000).

Após esse primeiro contato com o Colégio Cenecista, iniciamos a execução da segunda oficina, momento em que focamos nossas atenções precisamente nas referências culturais do sertão de Alagoas e da cidade em que estava localizada a escola, a partir das 100 imagens já selecionadas. As mesmas foram projetadas para que os alunos identificassem as cinco categorias estabelecidas pelo Manual do INRC (IPHAN, 2000). À medida que as imagens eram apresentadas, surgiam diversos comentários sobre o que elas representavam para eles e para a cidade. Foram identificados celebrações, ofícios e modos de fazer, mas as referências que mais se destacaram na fala dos alunos e professores foram as edificações e os lugares.

Depois de uma reflexão sobre as referências culturais representadas nas fotografias, os alunos e professores das escolas preenchiam a Ficha de Identificação sugerida pelo Manual do INRC (INRC). Cabe destacar que as fichas do INRC são bastante complexas. Primeiro, porque elas abordam cada uma das referências culturais, lugares, celebrações (dentre outras) de forma separada, ou seja, para cada referência existe uma ficha específica. Em segundo lugar, porque cada uma delas solicita uma ampla variedade de informações de fontes e origens diversas (fotografias, relatos de entrevista, descrição técnica de localização e incidência de determinada prática cultural), que são compiladas e apresentadas, como bem observa Arantes Neto (2000), por meio de uma descrição densa e sistemática. Nesse sentido, optamos por sintetizar, ou simplificar, as informações solicitadas para 0 preenchimento das fichas de cada referência cultural, colocando-as todas em um só documento. Ao invés de ter em mãos uma ficha para cada uma das referências culturais, os estudantes e professores tinham apenas uma ficha de duas páginas, em que era solicitada uma identificação, seguida de uma descrição resumida, das referências culturais locais. 
Finalizando esse trabalho de identificação, a equipe executora ligada à UFAL recolhia as fichas preenchidas por eles e realizava uma classificação das referências que apresentavam maior ocorrência. Selecionamos um número de 30 imagens para montar a exposição, as quais foram trabalhadas de acordo com o INRC (IPHAN, 2000). Entre as imagens selecionadas, destacamos as fotografias que foram escolhidas pelo Colégio Cenecista, para lançar uma reflexão sobre o processo de identificação das referências culturais locais e o potencial do INRC como uma metodologia participativa a ser trabalhada em escolas 5 .

\section{Memória e história: olhares sobre o sertão alagoano}

Uma das fotografias que mais chamou a atenção dos alunos foi esta vista da cidade de Santana do Ipanema.

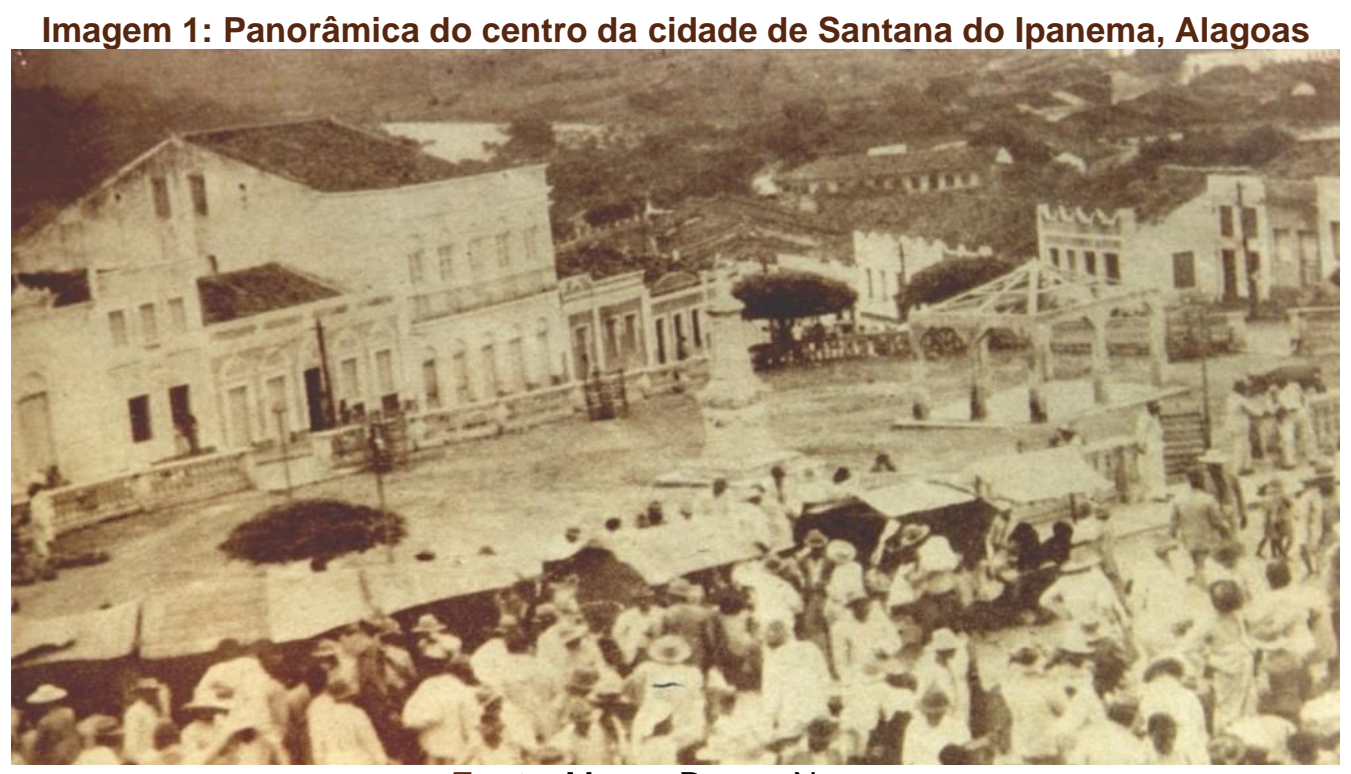

Fonte: Museu Darras Novas.

No decorrer das oficinas, alunos e professores fizeram referência a estas edificações como sendo uma marca da cidade. Nos relatos dos alunos, ela aparece como sendo uma representação dos tempos em que o município tinha uma vida cultural pulsante. Ao se debruçarem sobre essa imagem, observaram que as antigas edificações já não existem mais. Nesse sentido, lembraram-se da importância do antigo cinema da cidade. Rememoraram as narrativas dos seus familiares mais velhos sobre a agitada vida cultural do passado, nos tempos em que o cinema era uma das principais distrações locais. Lembraram também do fechamento do cinema e da sua posterior transformação em

\footnotetext{
5 Após a ampla divulgação do Manual do INRC e sua posterior aplicação em diferentes contextos, foram identificados alguns problemas de ordem técnica sobre a tradução das falas dos grupos envolvidos diretamente com os bens culturais inventariados pelo IPHAN. Verificou-se, também, a necessidade de se proceder a possíveis revisões dessa metodologia frente aos resultados acumulados ao longo dos anos de sua aplicação e ainda sobre os processos de mercantilização e construção de identidades que giram em torno da aplicação desta metodologia. Para abordagens teóricas dedicadas a esse tipo de problemática, ver Morais, Ramassote e Arantes Neto (2015).
} 
um centro comercial. Nesse momento, tanto entre os alunos da UFAL e das escolas como entre os seus professores, foi unívoco o questionamento sobre o fechamento do cinema.

Ao aplicar o INRC (IPHAN, 2000), em diálogo com Arantes Neto (2000), Fonseca (2000), Varine (2002) e Rodrigues (2012) percebemos que os participantes pareciam se sentir imbuídos de legitimidade social para tratar das representações desta imagem, ou seja, o contexto de sua produção, as marcas do tempo na cidade e, mais ainda, refletir o impacto da perda do cinema para a vida cultural local e sua posterior transformação em centro comercial. Além disso, foi possível observar, a partir da fotografia, que eles possuem um repertório de vivências, informações e, especialmente, memórias, transmitidas oralmente entre as gerações.

O INRC (IPHAN, 2000) tem, portanto, o potencial de evocar essas memórias herdadas pelos alunos e professores, contribuindo, inicialmente, para ressignificar as identidades dos envolvidos no projeto. A partir desta experiência de aplicação do INRC os alunos e os professores da escola aprenderam que a memória também pode ser tratada em sua dimensão social, especialmente em seu papel de organizar as lembranças individuais em prol de um sentimento coletivo de pertencimento a um território.

A partir da fotografia, outras edificações foram sendo numeradas pelos alunos e professores: 0 antigo teatro, que também já não existe mais, as casas ligadas à elite econômica local, que ainda hoje guardam a memória de personagens importantes para a cidade: políticos, artistas, escritores, médicos. Essas lembranças e memórias se voltam para um tempo não necessariamente vivenciado por eles, ou seja, a função das edificações a que eles se referiram não é mais a mesma do presente. Isso permite refletir, assim como chama atenção o manual do INRC (IPHAN, 2000) e os autores que auxiliaram na sua elaboração (Arantes Neto, 2000; Corsino, 2000; Fonseca, 2000), sobre a capacidade das categorias apresentadas, junto ao aporte das fotografias, de evocar lembranças individuais, memórias coletivas e representações sociais, reforçando a sensação de pertencimento ao sertão alagoano e especialmente a cidade de Santana do Ipanema.

Essa vivência nos permite observar, como equipe executora, a importância das fotografias como aporte das memórias e histórias locais. Elas são um gatilho para ativar as lembranças individuais, estimulando-os a construírem narrativas comunitárias sobre o passado da cidade, utilizando as suas referências culturais locais. Seguindo a base argumentativa do próprio INRC (IPHAN, 2000), aprendemos ainda que as fotos se tornam um exemplo de como um objeto material pode ser utilizado como ponto de partida para produção de narrativas afetivas sobre o passado.

Essas edificações, observadas através do aporte fotográfico, expressam perfeitamente bem as significações históricas e de memória, tornando-se referências culturais centrais para os grupos de alunos e professores, não apenas pelo seu valor arquitetônico, como também pelas representações sociais a elas associadas: as narrativas sobre elas, sobre os usos que essas construções tiveram no passado e têm hoje.

Semelhante aos antigos palimpsestos - documentos formados por uma camada de tecido grosso, em que diferentes tipos de escrita se sobrepunham, à medida que as diferentes gerações eram 
incumbidas de atualizar as leis e regras de convivência social -, essas memórias são atualizadas de geração em geração, conectando o passado ao presente, imprimindo nessas edificações os significados atribuídos pelas pessoas através do tempo. Em diálogo com os autores que auxiliaram na elaboração do INRC (Arantes Neto, 2000; Fonseca, 2000; Corsino, 2000), essa experiência também nos possibilitou refletir, enquanto equipe executora, sobre o modo como a memória se torna um instrumento importante para a autoestima social, conferindo protagonismo aos estudantes para tratar de temas locais, associando-os às transformações ocasionadas com o passar do tempo e a modernização da cidade.

Tratando mais especificamente da categoria lugar (IPHAN, 2000), uma das fotografias que também despertou interesse do grupo envolvido nas oficinas foi esta abaixo:

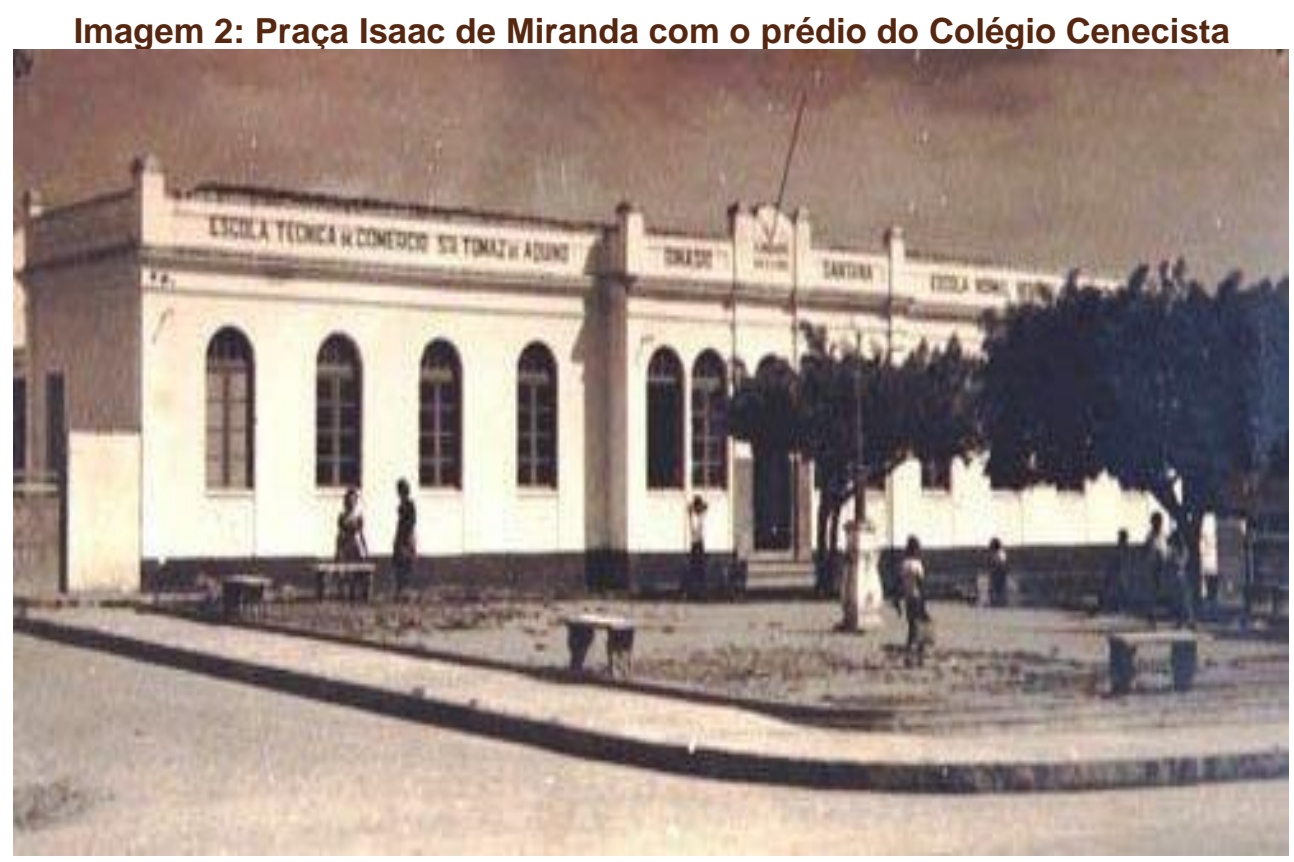

Fonte: Museu Darras Noya.

Ao projetarmos esta foto, os alunos e os professores foram tomados de muita emoção, pois se trata do prédio onde hoje funciona o Colégio Cenecista. Ele está localizado na Praça Doutor Isaac de Miranda, no centro da cidade de Santana do Ipanema. A imagem foi montada com duas referências culturais centrais da cidade: a praça, em primeiro plano e, em segundo, o prédio do colégio. Não é possível perceber nessa imagem, mas, ao lado direito, também existe uma pequena igreja, conhecida entre os habitantes da cidade como a Igrejinha. Segundo os alunos e os professores, tanto a Igrejinha, como o Colégio e a praça têm suas histórias conectadas a partir de um acontecimento que se instituiu como um marco da história local: a morte do cangaceiro Virgulino Ferreira, o Lampião, ícone do cangaço do Nordeste brasileiro. 
Patrimônio cultural na sala de aula: reflexões a partir da utilização de metodologias participativas em ações... Rafael de Oliveira Rodrigues e Roberta de Sousa Mélo

Imagem 3: Igrejinha onde foram expostas as cabeças do grupo de Lampião em Santana do Ipanema

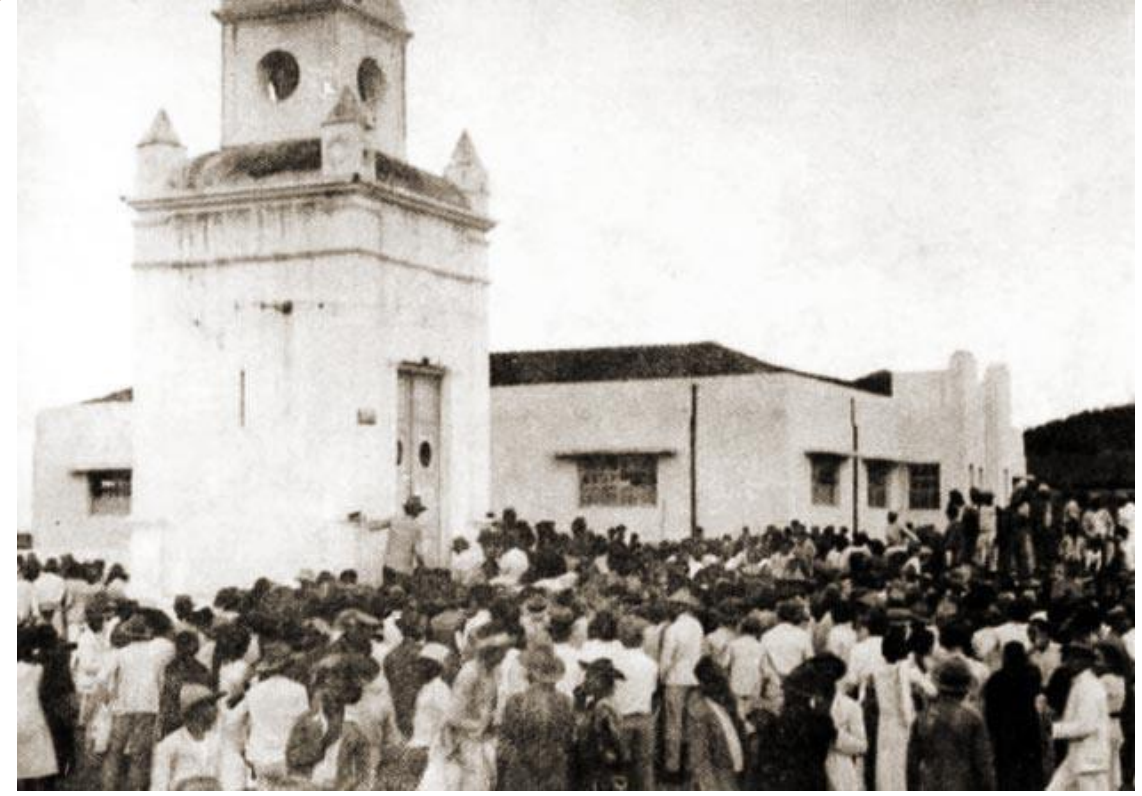

Fonte: Museu Darras Noya.

De acordo com a narrativa dos alunos e professores, as quais embasaram a escolha deste lugar como uma referência cultural da cidade, o prédio onde hoje funciona o colégio foi, no passado, a delegacia sede da volante responsável pela morte de Lampião, morto numa emboscada em uma fazenda em Angico, às margens do rio São Francisco, nas proximidades da cidade de Piranhas, também em Alagoas. Em outras palavras, o prédio do colégio foi um tipo de quartel da polícia da época, a qual se deslocava pelas veredas do sertão à procura dos cangaceiros que aterrorizavam as cidades nordestinas. Ainda segundo a narrativa dos alunos e professores, após a morte de Lampião e de mais alguns integrantes do grupo, as cabeças dos cangaceiros foram decepadas e expostas pelas cidades de Alagoas, como uma prova material do sucesso do Estado brasileiro em conseguir matar o mais famoso cangaceiro.

Imagem 4: Cabeças dos cangaceiros do bando de lampião expostas na cidade de Piranhas, sertão de Alagoas

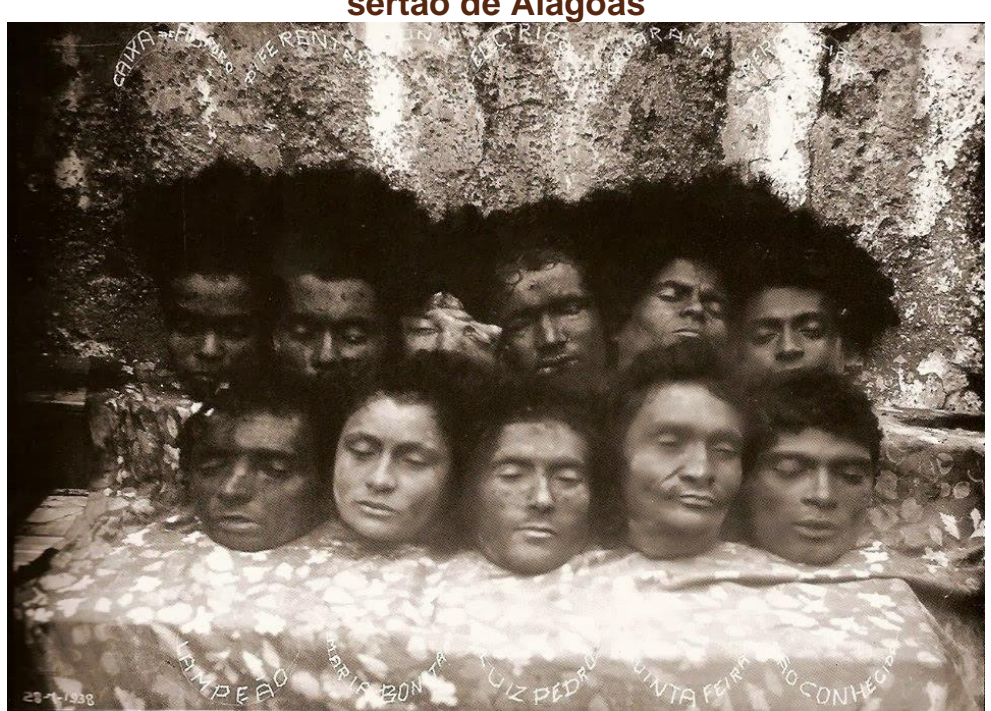

Fonte: Museu Darras Noya. 
A fotografia das cabeças do grupo acima foi feita na cidade de Piranhas, mas, apesar de não ter sido feita em Santana do Ipanema, ilustra bem o modo como os restos mortais foram tratados: como um troféu a ser ostentado pelo poder público da época. Nesse contexto, as cabeças também foram expostas em frente ao prédio do Colégio Cenecista do mesmo modo como foram expostas em Piranhas, como era previsto, já que o quartel de onde saíram os responsáveis pela morte dos cangaceiros estava localizado na cidade. Ao acessar esse repertório de referências locais, os alunos e professores relembram que a imagem 3 representa exatamente o momento em que as pessoas se aglomeravam para ver as cabeças do famoso grupo de cangaceiros. Descrevem, ainda, que foi exatamente nos degraus da Igrejinha, localizada em frente ao atual prédio do Colégio Cenecista, que as cabeças foram expostas. Algumas décadas após esse acontecimento, que ainda hoje marca o imaginário local, o prédio que abrigava o quartel foi transferido para outra localidade da cidade, e sua antiga sede deu espaço às instalações do colégio.

Ao voltar nosso foco de atenções para essa experiência com base no Manual do INRC e da literatura especializada (Arantes Neto, 2000; Corsino, 2000; Fonseca, 2000; Varine, 2002; Cerqueira, 2005; Rodrigues, 2012), percebemos que a Igrejinha e o antigo prédio do colégio conferem à praça 0 status de lugar de referência para os alunos e professores. Segundo Arantes Neto (2000), espaços como esse adquirem o status de lugar de referência porque possuem um sentido especial para a população da cidade. À medida que eles são apropriados e significados pela população local a partir de práticas, como, por exemplo, lazer, religião, trabalho, comércio e política, se tornam lugares centrais na construção das identidades culturais. Em se tratando especificamente da Praça, da Igrejinha e do Colégio é possível refletir que eles têm centralidade ímpar na política e na história da cidade, especialmente no sertão alagoano, como nos sugerem as rememorações em torno de episódios históricos descritos acima.

Ao trabalharem com essa fotografia do passado, representativa do movimento conhecido nos livros de história como banditismo social, que assolou o Nordeste do país nas primeiras décadas do século XX, os estudantes e professores observaram que, apesar da história do cangaço fazer parte do imaginário local, não existe conteúdo produzido na literatura historiográfica sobre o tema na cidade de Santana do Ipanema. Nesse momento, foi possível perceber uma grande euforia da parte deles ao se perceberem como agentes produtores de conhecimento sobre esse evento que ainda hoje marca a cidade. Ao tratarmos desse conhecimento produzido por eles em sala de aula, a partir da metodologia de inventário, é possível reconhecer que houve, por parte deles, um grande interesse pelo modo como o conhecimento sobre determinados acontecimentos é produzido pela historiografia.

Nesse sentido, pode-se entender, em diálogo com a literatura acerca das referências culturais (Arantes Neto, 2000; Fonseca, 2000; Corsino, 2000), que as lembranças articuladas em torno de determinados acontecimentos contribuem para a construção de uma memória social, a qual funciona como um auxílio no entendimento dos eventos históricos. Em outras palavras, aprendemos conjuntamente que, apesar da memória social, transmitida pela oralidade, não estar registrada oficialmente nos livros de história, ela também serve como fonte de conhecimento para historiografia, ao 
produzir ou questionar as narrativas sobre determinados eventos. Mais ainda: aprendemos que essas narrativas, que expressam saberes próprios, produzidos, adquiridos e permutados entre os indivíduos em suas vivências e vínculos sociais, podem auxiliar o conhecimento historiográfico a rever determinados acontecimentos, ou mesmo o modo como eles foram produzidos e hoje se encontram documentados nas fontes oficiais como os arquivos, os museus e os livros de história.

Em contrapartida, nós, da equipe executora do projeto, percebemos que, assim como as fotografias, as edificações e os lugares de referência são marcos materiais no tempo e no espaço, elementos que auxiliam na organização das memórias sociais, ao mesmo tempo em que contribuem para reforçar o sentido de pertencimento à cidade, por parte dos seus habitantes. Disso depreende-se que é possível falar de temas mais amplos, como a construção da identidade nacional, ou mesmo da história nacional, a partir de referências locais que se desvendaram durante a aplicação da metodologia de inventário, que falam também do que foi elaborado e compartilhado a partir das posicionalidades dos indivíduos nas paisagens culturais.

Após a seleção das imagens representativas da cultura local, a equipe executora, juntamente com os alunos e professores da escola, deu início à montagem da exposição fotográfica "Memória e História: olhares sobre o sertão alagoano", com curadoria compartilhada entre alunos e professores. O local escolhido para a exposição foi a Casa da Cultura, localizada no centro da cidade de Santana do Ipanema.

As imagens selecionadas para a exposição fotográfica foram ampliadas, além de terem algumas imperfeições corrigidas, visando uma melhor qualidade para apresentação ao público. Depois disso, a exposição foi montada de acordo com as próprias categorias definidas pelo IPHAN (2000): celebrações, formas de expressão, ofícios e modos de fazer, edificações e lugares ${ }^{6}$, estando aberta ao público entre os dias 17 e 21 de julho de 2017.

Antes de finalizarmos esta seção, é importante destacar que a experiência de aplicação conjunta do INRC ainda possibilitou que os diferentes grupos de alunos e professores envolvidos na ação de extensão acessassem as etapas e procedimentos de organização de uma exposição fotográfica, participando de todo o processo de curadoria que envolve a seleção das fotografias, sua posterior catalogação e tratamento em diferentes categorias (lugares, edificações, etc.) e, por fim, a construção da narrativa expográfica com base em referências culturais locais.

\section{Educação e cidadania: potencial do INRC para o trabalho nas escolas}

É possível perceber que o INRC tem um grande potencial de contribuir para a educação nas escolas e, em decorrência disso, para a promoção de uma educação voltada para a cidadania. Sobre esse tema, Cerqueira (2005, p. 99) tem chamado atenção para o fato de que nas "duas últimas décadas

\footnotetext{
${ }^{6}$ Cabe destacar que a prefeitura da cidade, especialmente os responsáveis pela Biblioteca Breno Aciolly, como também da Secretária Municipal de Educação, Cultura, Turismo, Esporte, Lazer, Ciências, Tecnologia e Inovação, tiveram um papel central na exposição, viabilizando tanto a divulgação quanto o aparato logístico (aparelho de imagem e de som, espaços da casa da cultura, mas também externos da cidade).
} 
do século $X X$, a educação patrimonial cresceu como uma importante dimensão da formação dos cidadãos na democracia moderna, uma vez que estimula o fortalecimento da consciência do caráter público do patrimônio".

Em outras palavras, é possível perceber que,

Por meio da educação patrimonial, busca-se sensibilizar as comunidades sobre a importância de preservar a sua memória; mais que isso, busca-se gerar uma reflexão sobre as memórias dos diferentes grupos sociais, de modo que se perceba que patrimônio não é somente o monumento belo e notável que fala do passado de algumas elites, mas que patrimônio é, outrossim, todo símbolo de memória coletiva, do terreiro à igreja, do sobrado à senzala, das praças públicas aos prédios das escolas, dos antigos armazéns de bairro aos grandes teatros (Cerqueira, 2005, p. 100).

Como já observamos algumas linhas atrás, o INRC é uma ferramenta de ação social (Arantes Neto, 2000). Nesse sentido, ao participarem do processo de identificação de suas referências culturais, os alunos das escolas se tornam parte fundamental da produção de conhecimento sobre o sertão de Alagoas e, ao fim, sobre eles mesmos.

Tomar suas referências culturais no processo de produção participativa de conhecimento faz com que eles reflitam e adquiram consciência do caráter público do patrimônio cultural na formação de suas identidades e memórias, tornando-se cidadãos conscientes da importância da sua cultura e do seu passado para suas vidas, assim como para a própria história do país, num sentido mais amplo. Mais ainda: tornam-se conscientes dos efeitos do passado no presente, da constituição de suas identidades enquanto indivíduos, como também enquanto comunidade.

Desmistifica-se, assim como observam Arantes Neto (2000), Fonseca (2000), Varine (2002), Cerqueira (2005) e Gonçalves (2007), a ideia de que o patrimônio cultural se resume aos grandes monumentos representativos da nação, deslocando as suas percepções para a importância das suas referências cotidianas, como praças, edificações, e também para suas memórias do passado, ligadas a eventos importantes para região e para historiografia nacional, como o exemplo do cangaço.

Em tudo que o INRC (IPHAN, 2000) nos permite sensibilizar os alunos e professores para importância de suas memórias e do patrimônio cultural local, percebemos que houve um aprendizado sobre a importância de suas referências culturais para preservação e reelaboração de suas memórias e histórias, como também de elementos da própria paisagem urbana da cidade em que habitam.

Nesse processo de identificação de referências culturais e posterior montagem coletiva de uma exposição fotográfica, foram estimulados, ainda, a reconhecerem-se como portadores legítimos de um saber específico: suas histórias e suas memórias. E, sob essa mesma perspectiva, puderam identificarse em sua condição de agentes ativos na produção do conhecimento expográfico que conecta os fragmentos das histórias e das memórias do passado com o tempo presente.

Esse processo de aprendizado a partir da prática de pesquisa orientada pelas diretrizes do INRC é capaz de promover, como já sugerido, um aumento da autoestima social conferindo legitimidade e autonomia para que os envolvidos produzam uma reflexão crítica da sua realidade (especialmente 
sobre as transformações urbanas que contribuíram para diminuição da vida cultural de sua comunidade e de sua cidade) e da construção das suas identidades individuais e coletivas (especificamente da importância da cultura sertaneja para pensar a constituição de uma nação marcada pela diversidade cultural).

Resta salientar, em termos práticos, que o INRC possibilita incentivar os alunos e professores das escolas ao exercício da pesquisa, a partir do aprendizado de um método científico pautado pela observação, classificação, análise e interpretação de sua cultura, o que é fundamental, como observam Arantes Neto (2000), Varine (2002) e Cerqueira (2005), para uma formação cidadã a partir da reflexão crítica de sua realidade.

\section{Considerações finais}

Este artigo teve como objetivo lançar uma reflexão sobre o potencial da metodologia do Inventário Nacional de Referências Culturais (INRC) na prática educativa escolar. Parte da valorização das ações de extensão desenvolvidas nas Universidades Federais brasileiras, em especial a Universidade Federal de Alagoas (UFAL), para o compartilhamento do conhecimento, tratando especificamente da utilização de uma metodologia participativa para auxiliar na produção de conhecimento conjunto entre professores e alunos de escolas municipais.

Ao longo da aplicação do INRC foi possível observar que existe um problema central nas políticas públicas que tratam do patrimônio cultural brasileiro, a saber, o da ressonância, expresso no fato destas políticas, muitas vezes, seguirem os interesses instrumentais da política nacional e do setor do turismo em detrimento dos interesses dos grupos sociais que interagem diretamente com o patrimônio cultural. Diante disso, o INRC tem um grande potencial para dirimir esse problema, trazendo para a esfera de decisão destas políticas os próprios grupos envolvidos com os bens representativos do patrimônio cultural. Nesse caso, esse processo ocorre a partir das referências culturais desses grupos, que apesar de não estarem no rol das políticas públicas sobre o patrimônio cultural da nação no primeiro momento de sua aplicação, têm ganhado força a partir dos anos 1970, culminando no conceito de patrimônio imaterial nos anos 2000.

Ao voltar o foco das nossas atenções à aplicação do INRC para o trabalho na educação escolar, observamos que ele tem um grande potencial para a formação crítica dos alunos das escolas. Em primeiro lugar porque essa metodologia instiga os alunos a participarem de uma pesquisa, fomentando uma educação crítica e cidadã, fazendo com que eles se sintam agentes centrais na produção do conhecimento. Em segundo porque permite construir esse conhecimento tomando como base elementos das suas vivências, como, por exemplo, as histórias locais, as memórias herdadas de seus familiares, ou mesmo suas memórias recentes sobre o local em que habitam. Esse processo faz com que eles se percebam como legítimos portadores de um conhecimento específico acerca de suas histórias e da produção de suas próprias identidades culturais.

Sugerimos, portanto, que as referências culturais são um elemento importantíssimo no processo educativo e lançamos o desafio de trazer esses elementos culturais, somados a novas metodologias

\section{7}


participativas, para as práticas de ensino dentro das escolas, além de um maior estreitamento de laços entre as Universidades Federais e as escolas que existem no entorno destas instituições, para a promoção de uma educação pautada na produção coletiva do conhecimento.

\section{Referências}

ARANTES NETO, Antônio. Como ler o INRC. In: IPHAN. Inventário Nacional de Referências Culturais: manual de aplicação. Brasília: IPHAN, 2000, p. 27-34.

CERQUEIRA. Flávio Vergara. Patrimônio cultural, escola, cidadania e desenvolvimento sustentável. Diálogos, v. 9 , n. 1, p. 91-109, 2005.

CORSINO, Célia Maria. Apresentação. In: IPHAN. Inventário Nacional de Referências Culturais: manual de aplicação. Brasília: IPHAN, 2000, p. 23-26.

FONSECA, Cecília Londres. Referências Culturais: base para novas políticas de patrimônio In: IPHAN. Inventário Nacional de Referências Culturais: manual de aplicação. Brasília: IPHAN, 2000, p. 11-20.

GONÇALVES, José Reginaldo dos Santos. Antropologia dos objetos: coleções, museus e patrimônio. Rio de Janeiro: IPHAN, 2007.

IPHAN. Inventário Nacional de Referências Culturais: manual de aplicação. Brasília: IPHAN, 2000.

IPHAN. Inventário Nacional de Referências Culturais. IPHAN. 02 mar. 2009. Disponível em: https://bit.ly/32fMaRH. Acesso em: 25 jul. 2019.

LIMA FILHO, Manuel Ferreira. Da matéria ao sujeito: inquietação patrimonial brasileira. Revista de Antropologia da USP, v. 52, n. 2, p. 605-632, 2009.

MORAIS, Sara; RAMASSOTE, Rodrigo; ARANTES NETO, Antônio. Trajetória e desafios do Inventário Nacional de Referências Culturais (INRC): entrevista com Antônio Arantes. Revista CPC, n. 20, 221-260, 2015.

REIS, Victória; RODRIGUES, Rafael de Oliveira. Relações entre as políticas de patrimônio cultural e o turismo: olhares sobre as cidades de Penedo e Piranhas. In: SANTOS, Anderson Moreira Aristides dos; SANTOS, Anderson David Gomes dos; RODRIGUES, Rafael de Oliveira (Orgs.). Ensaios sobre a Economia do Sertão Alagoano. Jundiaí: Paco Editorial, 2019, [s./p.].

RODRIGUES, Rafael de Oliveira. Repensando as representações acerca do patrimônio histórico: olhares sobre o tombamento de uma antiga base de atracação de Zeppelins. In: TAMASO, Isabela; LIMA FILHO, Manuel Ferreira (Orgs.). Antropologia e Patrimônio Cultural: trajetórias e conceitos. Brasília: ABA Publicações, 2012, p. 319-342.

VARINE, Hugues de. Patrimônio e educação popular. Revista Ciências e Letras, n. 31, p. 287-296, 2002. 